\title{
Iliopsoas Muscle Hematoma Secondary to Alcoholic Liver Cirrhosis
}

\author{
Suguru Yamashita Nobutaka Tanaka Yukihiro Nomura \\ Takuya Miyahara Takatoshi Furuya \\ Department of Surgery, Asahi General Hospital, Asahi, Japan
}

\section{Key Words}

Iliopsoas $\cdot$ Muscle hematoma $\cdot$ Liver cirrhosis

\begin{abstract}
Iliopsoas muscle hematoma in a patient with alcoholic liver cirrhosis is rarely seen, however it has a high mortality. Thus we should cautiously make a diagnosis and treatment. This is the case of a 60-year-old male. He had a 15-year history of alcoholic liver disease and emphysema. He presented with low back pain after a fall that had happened 2 months before. Due to persistent back pain, he went to see a local physician who, after detailed examination, suspected rupture of bilateral common iliac artery aneurysms and transferred the patient to our hospital. The same presumptive diagnosis was made, and on this basis, an aortic bifemoral Y-graft was implanted. He developed aspiration pneumonia and hepatic and renal dysfunction postoperatively, which led to multiple organ failure and subsequent in-hospital death on postoperative day 62. This was believed to be a case of iliopsoas muscle hematoma developed in a patient with liver cirrhosis, and considering it was a case with poor surgical risk, a conservative treatment option such as transcatheter arterial embolization should also have been considered. Although iliopsoas muscle hematoma with alcoholic liver cirrhosis is rare, an appropriate treatment plan should be determined on a case-by-case basis despite its poor prognosis.
\end{abstract}

\section{Introduction}

This is the case of a patient with alcoholic liver cirrhosis (LC) who underwent emergency surgery for iliopsoas muscle hematoma and subsequently died in the hospital. Intramuscular hematoma is classified as either spontaneous or traumatic. Causes of the former include hemorrhage diseases, neoplasm and arterial diseases. Iliopsoas muscle hematoma is well known as a major and well-documented complication of hemophilia and anticoagulant therapy [1, 2]. It encompasses a 
wide spectrum of severity (self-limiting to fatal) depending of its size, etiology and the development of complications. The difficulties in the correct diagnosis frequently lead to delay in treatment or unneeded surgery. Although LC is commonly associated with coagulopathy, including thrombocytopenia and hypoprothrombinemia, iliopsoas hematoma in LC patients has been rarely reported. However a high mortality rate has been reported in patients with intramuscular hematoma secondary to LC, especially alcoholic LC. It is important to take into account the characteristics of alcohol-related liver injury, such as the dysfunctional hemostasis due to fragile vascular walls, the inhibition of platelet adhesion to fibrinogen and the promotion of atherosclerosis.

We herein present a case of bilateral iliopsoas hematoma mimicking rupture of iliac artery aneurysm in a patient with alcoholic LC and review the literature on iliopsoas muscle hematoma associated with LC. Although rare, it is a condition with a poor prognosis, and a treatment plan should be carefully determined on a case-by-case basis.

\section{Case Report}

The patient was a 60-year-old male. He had a history of alcoholic liver disease and emphysema since 45 years of age. He consumed $60 \mathrm{~g}$ of alcohol per day and smoked 20 cigarettes per day. He suffered from back pain after a fall that had happened 2 months before. A local orthopedic surgeon examined him and prescribed non-steroidal anti-inflammatory drugs with follow-up observation. He then visited a local physician as he developed numbness and sense of weakness of the left thigh, and he was subsequently hospitalized. His back pain persisted. Gradually, he developed worsening anemia and hypotension. Rupture of bilateral common iliac artery an eurysms was suspected after computed tomography (CT) without contrast was conducted due to abnormal renal function, and the patient was transferred to our hospital while being administered catecholamines.

On admission, he was awake and alert with a blood pressure of 106/76 mm Hg and a heart rate of $133 \mathrm{bpm}$. The patient's laboratory data upon admission to our hospital (table 1) showed hemorrhagic anemia, hypoalbuminemia, hepatorenal dysfunction and coagulation abnormalities as follows: hemoglobin $5.3 \mathrm{~g} / \mathrm{dl}$, serum albumin $1.9 \mathrm{~g} / \mathrm{dl}$, aspartate aminotransferase $598 \mathrm{IU} / \mathrm{l}$, alanine aminotransferase $148 \mathrm{IU} / \mathrm{l}$, lactate dehydrogenase $873 \mathrm{IU} / \mathrm{l}$, platelet count $6.6 \times 10^{4} / \mu \mathrm{l}$, prothrombin time $46 \%$, activated partial thromboplastin time $>120$ s and creatinine $2.4 \mathrm{mg} / \mathrm{dl}$. The C-reactive protein level was increased $(6.0 \mathrm{mg} / \mathrm{dl}$ ) and electrolyte disturbances were shown (sodium $122 \mathrm{mmol} / \mathrm{l}$ and potassium $5.6 \mathrm{mmol} / \mathrm{l}$ ). In the non-contrast CT performed by the previous physician, bilateral iliopsoas muscles were enlarged with huge hematoma with a maximal diameter of $7 \mathrm{~cm}$ accompanied by formation of fluid level (fig. 1a), and the border between the bilateral iliac arteries and the hematoma was not clear (fig. 1c). Severe emphysema was also observed (fig. 1b). The patient was immediately admitted and an emergency operation was performed while administering red cell concentrates. It took $57 \mathrm{~min}$ from the start of patient transfer to that of operation, and $80 \mathrm{~min}$ from the start of the operation to aortic clamping.

As for the operation findings, bilateral retroperitoneal hematomas were seen below the aortic bifurcation, and the bilateral external iliac artery and internal iliac artery were not id entifiable within the hematomas. For this reason, iliac artery aneurysm could not be confirmed. An aortic bifemoral Y-graft was implanted and hematoma evacuation was not conducted. Operative time and intraoperative blood loss were $247 \mathrm{~min}$ and $1,010 \mathrm{ml}$, respectively. As for blood transfusion, $980 \mathrm{ml}$ of packed blood cells and $960 \mathrm{ml}$ of fresh frozen plasma were used.

As for the postoperative course (fig. 2), the patient was extubated and feeding was started on postoperative day 4; however, he developed aspiration pneumonia. Although antibiotic treatment was started, the patient developed Clostridium difficile colitis. Although postoperative progression of anemia was not observed using hematological drugs appropriately, follow-up CT on postoperative day 14 revealed that the sizes of bilateral iliopsoas muscle hematomas were almost the same as before the operation. He then developed methicillin-resistant Staphylococcus aureus colitis, paralytic ileus and ascites. An ileus tube was placed (fig. 3 ); however, the patient deteriorated with vomiting 
and worsening aspiration pneumonia. Thus, he was re-intubated for ventilator management. Tracheotomy was conducted and pneumonia treatment was continued; however, the patient progressively deteriorated with liver dysfunction, accumulating ascites and intravascular volume depletion. Although his renal failure became irreversible, dialysis treatment was declined by his family members, and the patient died on postoperative day 62. Autopsy was not performed on request of the family.

\section{Discussion}

LC is commonly associated with coagulopathies, including thrombocytopenia and hypoprothrombinemia, which often cause easy bruising and bleeding [3]. Sudden bleeding from gastrointestinal varices due to portal hypertension is also an established risk of LC. Although muscle hematoma usually occurs either traumatically or spontaneously in patients with hemophilia and in patients receiving anticoagulant therapy, it is rare in cirrhosis [4]. However, Sugiyama et al. [5] reported that the mortality rate of muscle hematoma in LC patients is extremely high in comparison to that in patients with hemophilia or under anticoagulant treatment and that these findings characterize muscle hematoma. Actually the mortality rate of iliopsoas hematoma associated with hemophilia is extremely low after the induction of prophylaxis [2], and according to a review of iliopsoas hematomas in patients receiving intravenous heparin, only 1 of 54 patients (1.9\%) died [6]. In these reports, it was generally accepted that early recognition and diagnosis of iliopsoas hematoma could reduce mortality.

Retrospective analysis of this case led to the consideration that bilateral iliopsoas muscle hematoma in this patient with alcoholic LC was caused either spontaneously or by trauma. We further studied cases of iliopsoas muscle hematoma accompanied by LC. During our search of Japanese and English articles previous published in medical journals, we found 7 other cases (table 2) [5, 7-12]. The median age of these patients including the present case was 58 years (range 48-62) and all patients were male. Alcoholic LC independently accounted for $75 \%$ ( 6 of 8 cases). A combination of hepatitis C- and alcohol-related LC and LC of unknown etiology were observed in 1 each out of 8 cases. This high rate of alcoholic LC was believed to be associated with hemorrhagic tendencies due to dysfunctional coagulation with LC as well as dysfunctional hemostasis due to fragile vascular walls caused by alcohol. Huang et al. [13] also reported that the overall incidence of spontaneous intracranial hemorrhage in LC was related to the etiology of LC, and the incidence was 6 times higher in alcohol-related LC than in virus-related LC. It seems likely that a common risk factor, namely alcohol, plays an important role in the promotion of non-variceal hemorrhage in LC patients. Several actions of alcohol may promote hemorrhage, including the inhibition of platelet adhesion to fibrinogen [14], dose-related ethanol suppression of platelet aggregation induced by extravasation [15] and the promotion of atherosclerosis [16].

Symptoms were frequently reported to include acute groin pain and femoral neuropathy [5]. In our analysis of the previous literature, general fatigue and low back pain were often observed as a primary symptom (50 and 37.5\%, respectively) (table 2). As for the trigger of developing iliopsoas muscle hematoma in LC patients, 6 of 8 cases $(75 \%)$ revealed spontaneity and the others $(25 \%)$ contusion. Diagnosis was usually 
made by CT, ultrasonography or angiography. However, case 1 was properly diagnosed with iliopsoas muscle hematoma only after getting the autopsy findings [5].

Treatment options include conservative therapy (such as clotting factor replacement), transcatheter arterial embolization (TAE) or hematoma removal. In this case, we had no choice but to perform the emergent operation without being able to obtain a CT image with contrast due to the patient's renal dysfunction. Even during the operation, iliac artery aneurysm could not be confirmed; however, we proceeded with aortic bifemoral Y-grafting as rupture of aneurysm could still not be excluded. As for the treatment strategy of iliopsoas muscle hematoma with LC, there is no standard therapy; however, a treatment plan should be carefully determined on a case-by-case basis. Because of the serious underlying condition, 5 of the 8 reported cases (62.5\%) led to in-hospital deaths. In this case, we could not reach a definitive diagnosis of iliopsoas muscle hematoma on admission. Considering that this patient was a poor surgical risk case, conservative therapy such as TAE should have been considered. In suited patients, Zissin et al. [17] reported that 19 of 26 patients (73\%) recovered following TAE in anticoagulant-related rectus abdominis and iliopsoas hematoma. However, an unsuccessful case of TAE was also reported in an unsuited patient [9]. Urgent liver transplantation, which was reported by Yamamoto et al. [18], might be a treatment choice in the future. Taking into account its extremely high mortality rate, iliopsoas muscle hematoma should be recognized as a rare but clinically important bleeding complication of LC patients, especially in cases of alcoholic LC.

In conclusion, iliopsoas muscle hematoma in patients with LC is rare but should not be overlooked, and an appropriate treatment plan should be determined on a case-by-case basis despite its poor prognosis.

\section{Disclosure Statement}

None of the authors have any conflicts of interest associated with this study. No grant support or other funding was received. 
$\underline{\text { Table } 1 . ~ B l o o d ~ t e s t ~ f i n d i n g s ~ o n ~ a d m i s s i o n ~}$

\begin{tabular}{ll}
\hline Alb & $1.9 \mathrm{~g} / \mathrm{dl}(3.9-4.9 \mathrm{~g} / \mathrm{dl})$ \\
T-bil & $0.3 \mathrm{mg} / \mathrm{dl}(0.2-1.0 \mathrm{mg} / \mathrm{dl})$ \\
AST & $598 \mathrm{IU} / \mathrm{l}(10-40 \mathrm{IU} / \mathrm{l})$ \\
ALT & $148 \mathrm{IU} / \mathrm{l}(5-45 \mathrm{IU} / \mathrm{l})$ \\
$\mathrm{BUN}$ & $28.0 \mathrm{mg} / \mathrm{dl}(7.2-20.0 \mathrm{mg} / \mathrm{dl})$ \\
$\mathrm{Cre}$ & $2.4 \mathrm{mg} / \mathrm{dl}(0.5-1.1 \mathrm{mg} / \mathrm{dl})$ \\
$\mathrm{Na}$ & $122 \mathrm{mmol} / \mathrm{l}(136-145 \mathrm{mmol} / \mathrm{l})$ \\
$\mathrm{K}$ & $5.6 \mathrm{mmol} / \mathrm{l}(3.6-4.8 \mathrm{mmol} / \mathrm{l})$ \\
$\mathrm{Cl}$ & $92 \mathrm{mmol} / \mathrm{l}(99-109 \mathrm{mmol} / \mathrm{l})$ \\
$\mathrm{LDH}$ & $873 \mathrm{IU} / \mathrm{l}(120-245 \mathrm{IU} / \mathrm{l})$ \\
$\mathrm{ALP}$ & $201 \mathrm{IU} / \mathrm{l}(104-338 \mathrm{IU} / \mathrm{l})$ \\
$\gamma$-GTP & $100 \mathrm{IU} / \mathrm{l}(16-73 \mathrm{IU} / \mathrm{l})$ \\
CRP & $6.0 \mathrm{mg} / \mathrm{dl}(<0.3 \mathrm{mg} / \mathrm{dl})$ \\
WBC & $4,700 / \mu \mathrm{l}(3,100-9,500 / \mu \mathrm{l})$ \\
Hb & $5.3 \mathrm{~g} / \mathrm{dl}(13.5-16.9 \mathrm{~g} / \mathrm{dl})$ \\
Plt & $6.6 \times 10^{4} / \mu \mathrm{l}\left(15.1-34.9 \times 10^{4} / \mu \mathrm{l}\right)$ \\
PT & $46 \%(70-130 \%)$ \\
APTT & $>120 \mathrm{~s}(24-38 \mathrm{~s})$ \\
HBsAg & $(-)$ \\
HCVAb & $(-)$ \\
\hline
\end{tabular}

Values in parentheses are normal ranges in our institution. All data were collected during the fasting state.

Table 2. Reported cases of iliopsoas muscle hematoma in LC

\begin{tabular}{|c|c|c|c|c|c|c|c|c|}
\hline Case & $\begin{array}{l}\text { Age, } \\
\text { years }\end{array}$ & Gender & $\begin{array}{l}\text { Etiology of } \\
\text { LC }\end{array}$ & $\begin{array}{l}\text { Primary } \\
\text { symptom }\end{array}$ & Trigger & $\begin{array}{l}\text { Diagnostic } \\
\text { procedure }\end{array}$ & Treatment & Course \\
\hline $1[5]$ & 56 & M & alcohol & fatigue & spontaneous & autopsy & conserv. & died \\
\hline $2[7]$ & 59 & M & alcohol & LBP, leg pain & contusion & enhanced CT, AG & TAE & alive \\
\hline $3[8]$ & 60 & M & alcohol & fatigue, LAP & spontaneous & US, plain CT & conserv. & died \\
\hline $4[9]$ & 62 & M & alcohol + HCV & tarry stool & spontaneous & enhanced CT, AG & $\mathrm{TAE}$ & died \\
\hline $5[10]$ & 48 & M & alcohol & fatigue & spontaneous & US, plain CT & conserv. & alive \\
\hline $6[11]$ & 56 & M & alcohol & fatigue, LBP & spontaneous & enhanced CT & conserv. & died \\
\hline 7 [12] & 57 & M & unknown & groin pain & spontaneous & enhanced CT & $\begin{array}{l}\text { hematoma } \\
\text { removal }\end{array}$ & alive \\
\hline 8 (present) & 60 & M & alcohol & LBP & contusion & US, plain CT & operation & died \\
\hline
\end{tabular}

$\mathrm{AG}=$ Angiography; conserv. = conservative treatment including use of hematological and hemostatic agents; HCV = hepatitis C virus; LAP = low abdominal pain; LBP = low back pain; US = ultrasonography. 


\begin{tabular}{r|l|l|l}
$\begin{array}{r}\text { Case Reports in } \\
\text { Gastroenterology }\end{array}$ & $\begin{array}{l}\text { Case Rep Gastroenterol 2012;6:704-711 } \\
\text { DOI: 10.1159/000345391 }\end{array}$ & $\begin{array}{l}\text { Published online: } \\
\text { November 8, 2012 }\end{array}$ & $\begin{array}{l}\text { @ 2012 S. Karger AG, Basel } \\
\text { ISSN 1662-0631 } \\
\text { www.karger.com/crg }\end{array}$ \\
\hline
\end{tabular}
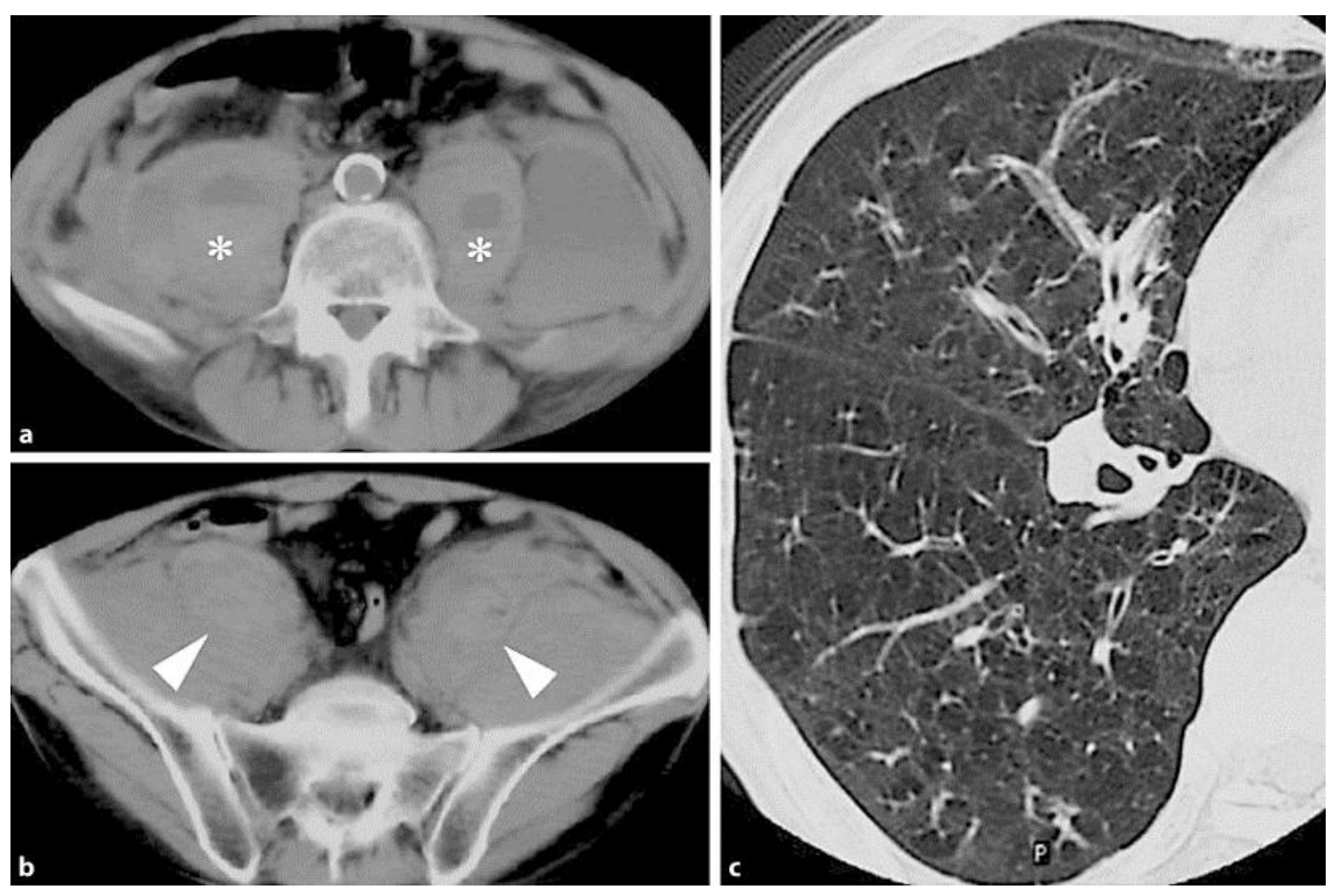

Fig. 1. a Enhanced abdominal CT showed that the bilateral iliopsoas muscles were enlarged with huge hematoma accompanied by formation of fluid level (asterisks). b Thoracic plain CT revealed severe emphysema (arrowheads). c The border between the bilateral iliac arteries and the hematoma was not clear. 


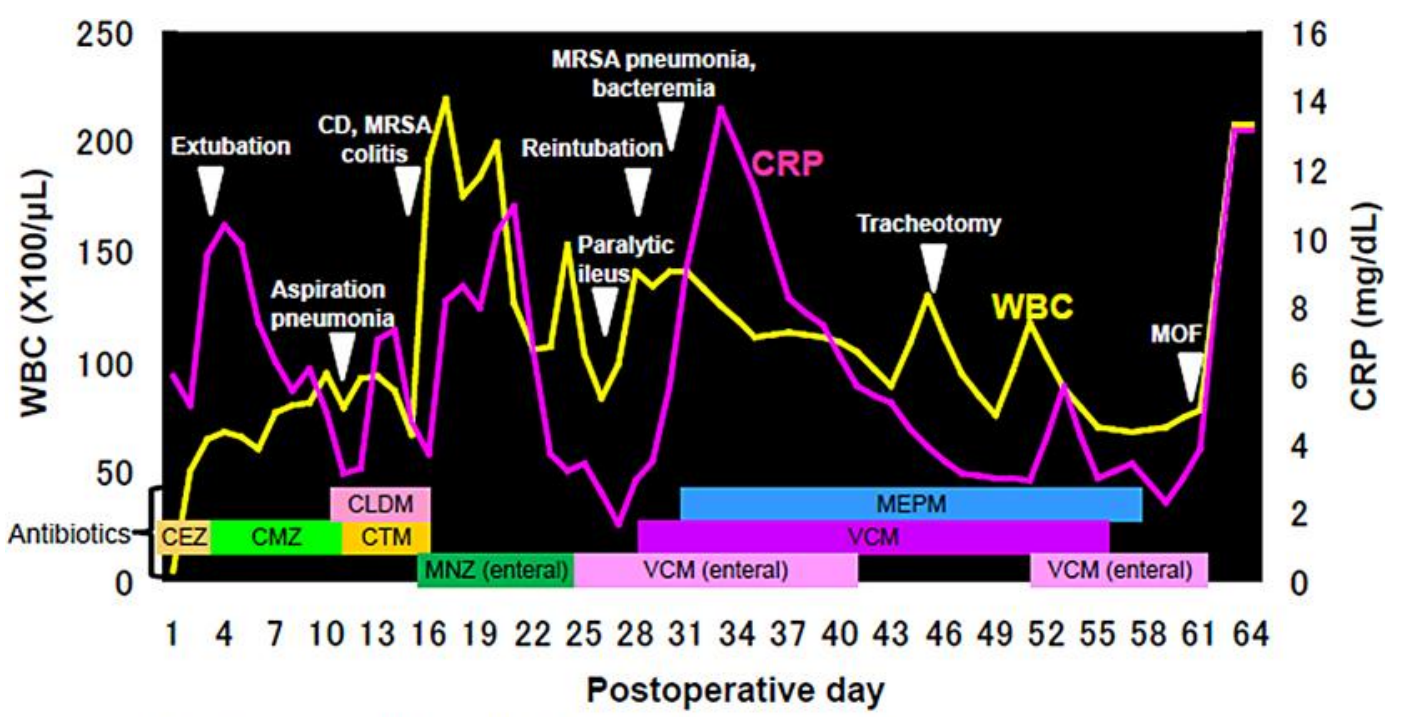

CD, Clostridium difficile; MRSA, methicillin-resistant Staphylococcus aureus; MOF, multiple organ failure; CEZ, Cefazolin Sodium Hydrate; CMZ, Cefmetazole Sodium; CLDM, Clindamycin Phosphate; CTM, Cefotiam Hydrochloride; MNZ, Metronidazole; VCM, Vancomycin Hydrochloride; MEPM, Meropenem Hydrate.

Fig. 2. Time course after emergent aortic bifemoral Y-grafting.

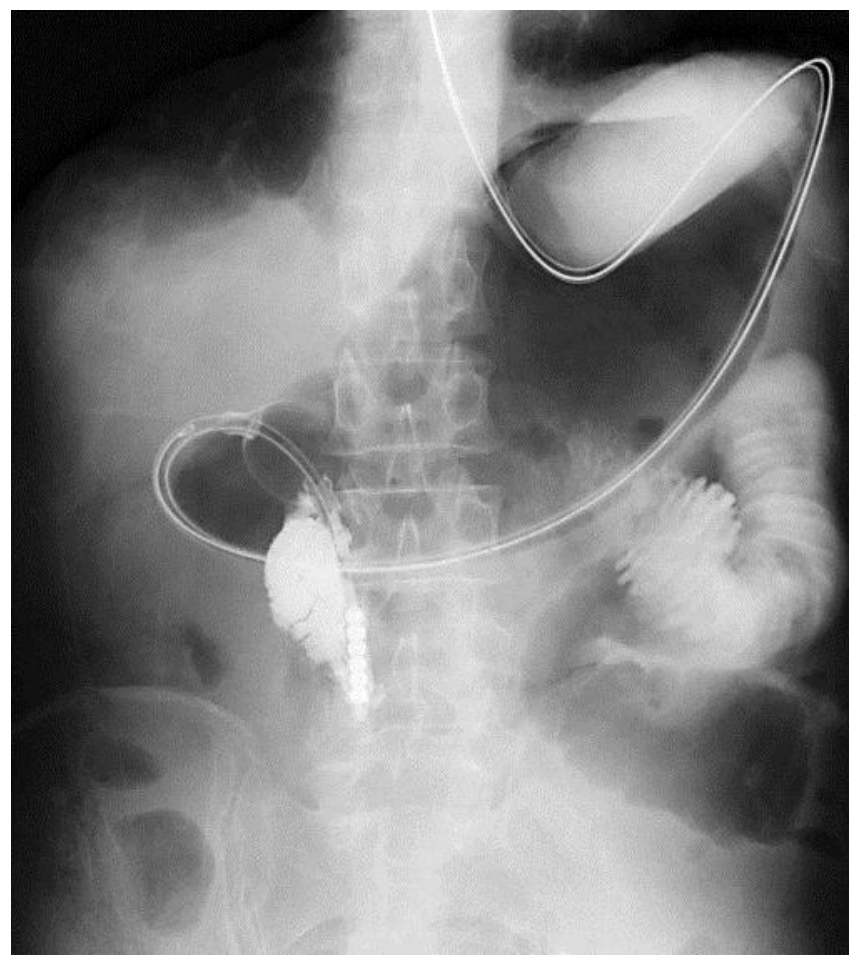

Fig. 3. An ileus tube was placed at the second portion of the duodenum for the paralytic ileus caused by $C$. difficile colitis and methicillin-resistant $S$. aureus colitis. 


\section{References}

$\checkmark 1$ Cherry WB, Mueller PS: Rectus sheath hematoma: review of 126 cases at a single institution. Medicine (Baltimore) 2006;85:105-110.

-2 Balkan C, Kavakli K, Karapinar D: Iliopsoas haemorrhage in patients with haemophilia: results from one centre. Haemophilia 2005;11:463-467.

-3 Craxì A, Cammà C, Giunta M: Clinical aspects of bleeding complications in cirrhotic patients. Blood Coagul Fibrinolysis 2000;11:S75-S79.

-4 Di Bisceglie AM, Richart JM: Spontaneous retroperitoneal and rectus muscle hemorrhage as a potentially lethal complication of cirrhosis. Liver Int 2006;26:1291-1293.

5 Sugiyama C, Akai A, Yamakita N, et al: Muscle hematoma: a critically important complication of alcoholic liver cirrhosis. World J Gastroenterol 2009;15:4457-4460.

6 Dauty M, Sigaud M, Trossaërt M, et al: Iliopsoas hematoma in patients with hemophilia: a single-center study. Joint Bone Spine 2007;74:179-183.

7 Ishihara Y, Nakae Y, Kanno T, et al: A case of iliopsoas hematoma associated with liver cirrhosis, management by transcatheter arterial embolization (in Japanese). Nihon Shokakibyo Gakkai Zasshi 2000;97:714-718.

-8 Kamura M, Tanahashi T, Yamakita N, et al: A case of idiopathic iliopsoas hematoma associated with liver cirrhosis (in Japanese). Nihon Shokakibyo Gakkai Zasshi 1998;95:1266-1269.

9 Yoshida H, Tsuji K, Kawakami H, et al: Two cases of alcoholic liver cirrhosis associated with intramuscular hematoma (in Japanese). Nihon Shokakibyo Gakkai Zasshi 2002;99:1350-1354.

10 Takasu 0, Nakane T, Nakamura A, et al: A case of idiopathic iliopsoas hemorrhage in an alcohol abuser effectively treated with vitamin K therapy (in Japanese). J Jpn Assoc Acute Med 2009;20:367-373.

11 Hiraoka A, Michitaka K, Shigematsu S, et al: A case of alcoholic cirrhosis complicated with iliopsoas hematoma: difficulty in discriminating the diagnosis of progressive anemia (in Japanese). Kanzo 2004;45:609-613.

12 Amakado E, Yasutake S, Yoshino M, et al: Iliopsoas hematoma associated with liver cirrhosis. A case report (in Japanese). Kanagawa J Orthop Traumatol 1991;4:165-167.

-13 Huang HH, Lin HH, Shih YL, et al: Spontaneous intracranial hemorrhage in cirrhotic patients. Clin Neurol Neurosurg 2008;110:253-258.

14 de Lange DW, Hijmering ML, Lorsheyd A, et al: Rapid intake of alcohol (binge drinking) inhibits platelet adhesion to fibrinogen under flow. Alcohol Clin Exp Res 2004;28:1562-1568.

15 Horak JK, Brandon TA, Ribeiro LG, et al: Effects of ethanol and hemolysis on in vivo and in vitro platelet aggregation. J Cardiovasc Pharmacol 1982;4:1037-1041.

16 Cooper DE, Goff DC Jr, Bell RA, et al: Is insulin sensitivity a causal intermediate in the relationship between alcohol consumption and carotid atherosclerosis? The insulin resistance and atherosclerosis study. Diabetes Care 2002;25:1425-1431.

17 Zissin R, Gayer G, Kots E, et al: Transcatheter arterial embolisation in anticoagulant-related haematoma - a current therapeutic option: a report of four patients and review of the literature. Int J Clin Pract 2007;61:1321-1327.

-18 Yamamoto S, Sato Y, Takeishi T, et al: Liver transplantation in an end-stage cirrhosis patient with abdominal compartment syndrome following a spontaneous rectus sheath hematoma. J Gastroenterol Hepatol 2004;19:118-119. 